\title{
Bacterial symbionts in animal development: arginine biosynthesis complementation enables larval settlement in a marine sponge
}

Hao Song, b, c, d, Olivia H Hewitt ${ }^{\mathrm{a}}$ and Sandie M Degnan ${ }^{\mathrm{a}}{ }^{\mathrm{a}}$

${ }^{\text {a }}$ School of Biological Sciences, The University of Queensland, Brisbane, 4072 QLD, Australia

${ }^{\mathrm{b}}$ CAS Key Laboratory of Marine Ecology and Environmental Sciences, Institute of Oceanology, Chinese Academy of Sciences, Qingdao 266071, China

${ }^{\mathrm{c}}$ Laboratory for Marine Ecology and Environmental Science, Qingdao National Laboratory for Marine Science and Technology, Qingdao 266071, China

${ }^{\mathrm{d}}$ Center for Ocean Mega-Science, Chinese Academy of Sciences, Qingdao 266071, China

*Corresponding author: Sandie M Degnan s.degnan@uq.edu.au

\section{SUMMARY}

Larval settlement and metamorphosis are regulated by nitric oxide (NO) signalling in a wide diversity of marine invertebrates (1-10). It is surprising, then, that in most invertebrates, the substrate for NO synthesis - arginine - cannot be biosynthesized but instead must be exogenously sourced (11). In the sponge Amphimedon queenslandica, vertically-inherited proteobacterial symbionts in the larva are able to biosynthesize arginine $(12,13)$. Here we test the hypothesis that symbionts might provide arginine to the sponge host so that nitric oxide synthase expressed in the larva can produce NO, which induces metamorphosis (8), and the byproduct citrulline (Fig. 1). First, we find support for an arginine-citrulline biosynthetic loop in this sponge larval holobiont using stable isotope tracing. In symbionts, incorporated ${ }^{13} \mathrm{C}$-citrulline decreases as ${ }^{13} \mathrm{C}$-arginine increases, consistent with the use of exogenous citrulline for arginine synthesis. In contrast, ${ }^{13} \mathrm{C}$ citrulline accumulates in larvae as ${ }^{13} \mathrm{C}$-arginine decreases, demonstrating the uptake of exogenous arginine and its conversion to NO and citrulline. Second, we show that while Amphimedon larvae can derive arginine directly from seawater, normal settlement and metamorphosis can occur in artificial sea water lacking arginine. Together, these results support holobiont complementation of the arginine-citrulline loop and NO biosynthesis in Amphimedon larvae, suggesting a critical role for bacterial symbionts in the development of this marine sponge. Given that NO regulates settlement and metamorphosis in diverse animal phyla (1-10) and arginine is procured externally in most animals (11), we propose that symbionts may play a equally critical regulatory role in this essential life cycle transition in other metazoans. 


\section{Background, Results and Discussion}

Larval settlement and metamorphosis are required for most marine invertebrates to complete their biphasic life cycle. These steps typically are initiated by the detection of environmental cues that indicate suitable habitat, and which in turn triggers signalling cascades that lead to behavioural and morphogenetic changes $(3,14,15)$. Nitric oxide (NO) is a gaseous signalling molecule that plays a conserved role in regulating larval settlement and metamorphosis in a diverse range of marine invertebrates, including ascidians, gastropod and bivalve molluscs, polychaete annelids, bryozoans, cirripedian crustaceans and demosponges, as either an inhibitor $(1-4,9,10)$ or an activator (5-8). In the marine sponge Amphimedon queenslandica, NO signalling induces larval settlement and metamorphosis (8) (Fig. 1A). However, arginine, which is a necessary precursor for NO synthesis, cannot be synthesized by $A$. queenslandica. Specifically, the genome of this sponge is missing genes encoding two necessary synthetases, namely argininosuccinate synthase, which converts citrulline into argininosuccinate, and argininosuccinate lyase, which catalyses arginine synthesis from argininosuccinate (16), although the gene encoded nitric oxide synthase (NOS) is present (Fig. 1B).

Although A. queenslandica adults can acquire arginine and other essential amino acids through their normal heterotrophic filter-feeding, sponge larvae are lecithotrophic (non-feeding) and therefore require another source of arginine to produce the NO necessary for settlement and metamorphosis. Potential sources of arginine in these non-feeding larvae are direct absorption from seawater and/or from symbiotic bacteria. A. queenslandica harbours a low complexity but stable bacterial community dominated by three proteobacterial symbionts - $A q S 1, A q S 2$ and $A q S 3$ - that are vertically transmitted with high fidelity from adults to embryos (12). All are present as extracellular symbionts in the inner cell mass of the larvae, with $A q S 1$ especially abundant (12) (Fig. 1C). Unlike A. queenslandica, the genomes of $A q S 1, A q S 2$ and $A q S 3$ indicate they are capable of synthesizing arginine from citrulline (13) (Fig. 1B), and thus have the potential to supply their sponge larval host with the arginine needed for NOS to produce NO.

\section{Amphimedon larval settlement occurs in arginine-free sea water}

Despite $A$. queenslandica lacking a complete arginine biosynthesis pathway, arginine is present in the free amino acid pool of multiple stages of the sponge life cycle, and is the most abundant free amino acid in the adult (Fig. S1). In swimming larvae, average arginine concentrations range from $0.053 \mathrm{nmol}$ in larvae recently emerged from the adult (0-2 hours post emergence, hpe) to 0.043 
nmol in larvae that are competent to settle (4-6 hpe; Fig. 2A). In comparison, arginine levels in natural seawater (collected from the native habitat of the sponge) and in artificial seawater (made from commercial sea salt), are 0.027 and $0.025 \mathrm{nmol} \mathrm{mL}^{-1}$, respectively (Fig. 2A). This means that approximately $1.75 \mathrm{ml}$ of sea water could theoretically supply the total arginine present in a single larva.

We tested whether larvae rely on this uptake of exogenous arginine from sea water to undergo settlement and metamorphosis. To do so, we reared larvae in artificial seawater that contained no amino acids, and thus no arginine (arginine free seawater, AF-SW). We found that larvae reared in AF-SW were still able to successfully settle and metamorphose when induced by coralline algae, and could do so at a rate similar to those reared in natural seawater (Fig. 2B). Given that the induction of settlement and metamorphosis by NO signalling (8) can only occur in the presence of arginine, this result suggests that $A$. queenslandica larvae are accessing arginine from a source other than the surrounding sea water to drive NO production. We hypothesised that this source could be the bacterial symbionts.

\section{Evidence of holobiont complementation of NO biosynthesis in Amphimedon larvae}

To test whether the symbiotic bacteria could be provisioning arginine for A. queenslandica larvae, we performed stable isotope-labelling with ${ }^{13} \mathrm{C}$-arginine and ${ }^{13} \mathrm{C}$-citrulline separately on sponge larvae and on bacterial symbionts. First, we incubated larvae in $10 \mu \mathrm{M}{ }^{13} \mathrm{C}$-labelled arginine in 0.22 $\mu \mathrm{m}$-filtered seawater (FSW), and then measured the relative abundance of ${ }^{13} \mathrm{C}$-citrulline and ${ }^{13} \mathrm{C}$ arginine in these larvae at 1 and $5 \mathrm{~h}$ post incubation using high performance liquid chromatography (HPLC) and liquid-chromatography-mass spectrometry (LC-MS) analysis. Although the ratio of ${ }^{13} \mathrm{C}$-arginine $/{ }^{12} \mathrm{C}$-arginine did not change over this period $(\mathrm{p}=0.130)$, we found a significant 5.7 -fold increase in the ratios of both ${ }^{13} \mathrm{C}$-citrulline $/{ }^{12} \mathrm{C}$-citrulline $(\mathrm{p}=0.005)$ and ${ }^{13} \mathrm{C}$-citrulline $/{ }^{13} \mathrm{C}$-arginine $\left(p=0.043\right.$ ) (Fig. 3). Since no ${ }^{13} \mathrm{C}$-citrulline was added in this experiment, the observed increase of ${ }^{13} \mathrm{C}$-citrulline must come from the labelled arginine; this demonstrates that the sponge larval holobiont can uptake arginine to produce NO and citrulline (Fig. 3). We observed a net arginine influx rate of $\sim 9.72 \mathrm{fmol}_{\text {larva }}^{-1} \mathrm{~h}^{-1}$ in the A. queenslandica larval holobiont, which is comparable to uptake rates of arginine and other free amino acids reported, for example, in Crassostrea gigas larvae (17).

Since citrulline can be synthesized by A. queenslandica (Fig. 1A), we next determined if the symbiotic bacteria can potentially use host-derived citrulline to biosynthesize arginine. To do this, 
we incubated an enriched symbiotic bacterial cell preparation with $10 \mu \mathrm{M}{ }^{13} \mathrm{C}$-labelled citrulline in FSW for $1 \mathrm{~h}$. We measured the relative abundance of citrulline and arginine in the bacteria at the time of introduction of ${ }^{13} \mathrm{C}$-labelled citrulline $(0 \mathrm{~h})$ as well as $4 \mathrm{~h}$ later. We found that the relative ratio of ${ }^{13} \mathrm{C}$-citrulline $/{ }^{12} \mathrm{C}$-citrulline decreased by approximately $47 \%(\mathrm{p}=0.025)$, while that of ${ }^{13} \mathrm{C}$ arginine $/{ }^{12} \mathrm{C}$-arginine increased approximately $53 \%(\mathrm{p}=0.016$, Fig. 3). Concurrently, the relative ratio of ${ }^{13} \mathrm{C}$-citrulline $/{ }^{13} \mathrm{C}$-arginine decreased approximately $70 \%(\mathrm{p}=0.003)$. Together, these results indicate that the symbiotic bacteria were uptaking the exogenous citrulline, and that a large proportion of this incorporated citrulline was rapidly converted into arginine.

\section{Conclusions}

Here we provide experimental evidence of metabolic complementation between A. queenslandica and its primary bacterial symbionts that appears necessary for settlement and metamorphosis, and thus completion of this sponge's life cycle. Specifically, these results are consistent with $A$. queenslandica larvae obtaining arginine, which is necessary for NO-induced settlement and metamorphosis (8), from its vertically-inherited symbiotic bacteria. Importantly, the ability of $A$. queenslandica larvae to metamorphose in arginine-free sea water is consistent with the symbionts, rather than seawater, being the primary source of arginine for the holobiont.

There appears to be at least two mechanisms by which symbiont-derived arginine could be acquired by $A$. queenslandica larval cells. First, the $A$. queenslandica genome encodes two cationic amino acid transporters (CATs) (Aqu2.1.32956_001 and Aqu2.1.32959_001; see http://metazoa.ensembl.org/Amphimedon_queenslandica/Info/Index) that are expressed in larvae and throughout the sponge life cycle (Fig. S2, data acquired from A. queenslandica developmental dataset NCBI accession GSE54364). Arginine synthesized by the symbiotic bacteria could be transported into sponge cells by these CATs. Second, sponge cells in larvae could acquire symbiont-derived arginine by phagocytosis and digestion of their symbiotic bacteria. Phagocytosis is a common mechanism by which animal host cells acquire nutrients from their symbionts (18), and occurs in diverse marine endosymbioses such as the annelid Olavius algarvensis (19) and the deep-sea clam Calyptogena magnifica (20,21). Given that we have frequently observed phagocytosis of the dominant bacterial symbionts in A. queenslandica larvae and early postlarvae (12), we propose this as another potential pathway by which the sponge larva can acquire arginine from its symbiotic bacteria. 
NO regulates settlement and metamorphosis in diverse marine invertebrates, including species of ascidians, gastropod and bivalve molluscs, polychaete annelids, bryozoans, cirripedian crustaceans and demosponges (1-10). NO can either repress or activate metamorphosis depending on the species, and these opposing activities are correlated neither with larval type (i.e. non-feeding lecithotrophs vs feeding planktotrophs) nor with phylogenetic position in the animal kingdom. Amongst these marine invertebrates, the arginine biosynthesis pathway is known only for the ascidian Ciona intestinalis (11) and A. queenslandica (this study), and in both cases appears to be incomplete. The same is true for the model invertebrates the fruit fly Drosophila melanogaster, the mosquito Anopheles gambiae and the nematode Caenorhabditis elegans (11). Given the apparent widespread requirement for an exogenous source of arginine for the biosynthesis of NO, and the role of NO in regulating settlement and metamorphosis, our study suggests that production of arginine by symbionts may be necessary for the completion of a diversity of marine invertebrate life cycles.

\section{Acknowledgements}

The authors thank Manuel Plan, Gert Talbo and Terra Stark from the Australian Institute for Bioengineering \& Nanotechnology at the University of Queensland for assistance in HPLC and LCMS analysis, Davide Poli for guidance on bacterial cell enrichments, and Laura Rix for editorial assistance on an early draft of the manuscript. Heron Island Research Station provided logistical support for collection of animals. This research was funded by Australian Research Council grants DP110104601 and DP170102353 to S.M.D., and a Natural Science Foundation of Shandong Province travel grant ZR2019BD003, a China Postdoctoral Science Foundation grant 2019M652498 and China Scholarship Council visiting scholar grant to H.S.

\section{Author Contributions}

S.M.D. and H.S. conceptualized this project and the methodological strategies. H.S. conducted all of the isotope and larval settlement experimental work and data analysis, with advice from S.M.D. O.H. conducted the FISH for bacterial symbionts. H.S. prepared the original draft of text and figures, and S.M.D. made significant contributions to revising the text and figures. All authors read and approved the final draft.

\section{Declaration of Interests}

The authors declare no competing interests. 


\section{Methods}

\section{Larval collection}

Amphimedon queenslandica sponge adults were collected from Heron Island Reef, southern Great Barrier Reef, Australia ( $\left.23^{\circ} 27^{\prime} \mathrm{S}, 151^{\circ} 56^{\prime} \mathrm{E}\right)$ and maintained in flow-through ambient sea water aquaria at Heron Island Research Station. Adult sponges were induced to release larvae by mild heat treatment $\left(1-2{ }^{\circ} \mathrm{C}\right.$ above ambient temperature) for less than $2 \mathrm{~h}$ as previously described (22) and maintained in $500 \mathrm{ml}$ native seawater at ambient temperature and light until use in experiments.

\section{Fluorescence in situ hybridization (FISH)}

A. queenslandica larvae were fixed and stored in $70 \%$ ethanol, and embedded in paraffin wax for sectioning as described in 22 and 23. Embedded larvae were sectioned longitudinally to a thickness of $6 \mu \mathrm{m}$ and mounted. Prior to hybridisation, larval sections were rehydrated in a graded series (7020\% ethanol, 1X PBS) and rinsed with hybridisation buffer [HB: $0.9 \mathrm{M} \mathrm{NaCl}, 20 \mathrm{mM}$ Tris-HCl (pH 7.2), $0.01 \%$ SDS, $18 \%$ formamide (as described in 24 ). To visualise bacterial symbionts by FISH, we used the specifically designed oligonucleotide for AqS1 (5'CCCCAGAGTTCCCGGCCGAA3', 12) that was 5' end labelled with the indocarbocyanine fluorochrome, Cy3 (SigmaAldrich). This probe was dissolved in Ultrapure distilled water (Invitrogen) to $50 \mathrm{ng} \mu \mathrm{L}^{-1} .8 \mu 1 \mathrm{HB}$ was mixed with $1 \mu \mathrm{l} \mathrm{Cy3-labelled} \mathrm{probe} \mathrm{and} \mathrm{applied} \mathrm{to} \mathrm{individual} \mathrm{tissue} \mathrm{sections,} \mathrm{and} \mathrm{incubated} \mathrm{for} 3 \mathrm{~h}$ at $46^{\circ} \mathrm{C}$. Following hybridisation, samples were washed for $10 \mathrm{~min}$ at $48^{\circ} \mathrm{C}$ in prewarmed wash buffer [225 mM NaCl, $20 \mathrm{mM}$ Tris- $\mathrm{HCl}$ (pH 7.2), 0.01\% SDS (24)]. As a counter stain to enable visualisation of sponge cells, larval sections were counterstained with DAPI (4',6diamidino-2phenylindole, Sigma-Aldrich; 1:1000 $\mu$ L PBS dilution) and incubated for $15 \mathrm{~min}$ in the dark at room temperature. Slides were rinsed with $1 \mathrm{X}$ PBS and fresh water, dried, then mounted in ProLong Gold antifade reagent (Life Technologies) and cured in darkness overnight before visual analysis. FISH and DAPI stained bacterial and sponge cells were visualised using confocal microscopy.

\section{Free amino acid extraction from sponge larvae, sponge adults and sea water}

For free amino acid extractions, larvae were sampled at $0 \mathrm{~h}$ post-emergence from the maternal adult sponge (hpe), and then again at 2, 4 and 6 hpe. At each time point, 10 larvae were placed in $800 \mu l$ of chilled $80 \%$ ethanol and $1 \mu$ of the internal standard norvaline ( $5 \mathrm{nmol}^{-1} \mathrm{l}^{-1}$ in water) (25) was 
added; this was replicated 5 times for each time point. Samples were then frozen at $-80^{\circ} \mathrm{C}$ until further processing. For free amino acid extraction from adult sponges, $\sim 4 \mathrm{~cm}^{3}$ tissue was dissected by scalpel from 4 individuals under sterile conditions, and gently squeezed to remove excess seawater. Tissue samples were weighed, $800 \mu$ of chilled $80 \%$ ethanol and $1 \mu 1$ norvaline solution were added, and samples were frozen at $-80^{\circ} \mathrm{C}$.

Larval and adult samples were homogenized with zirconia beads ( $2 \mathrm{~mm}$ ) at $4000 \mathrm{rpm}$ for $30 \mathrm{sec}$ using a Micro Smash MS-100 cell disrupter (Tomy Seiko Co., Ltd., Tokyo, Japan) and the homogenate centrifuged at $19,880 \mathrm{~g}$ for $10 \mathrm{~min}$ at $4^{\circ} \mathrm{C}$. The supernatant was dried using a vacuum centrifugal evaporator and then re-dissolved by in $10 \mu \mathrm{l} 500 \mu \mathrm{M}$ 1,2-amino butyric acid, $500 \mu \mathrm{M}$ sarcosine and $10 \mu 120 \%$ acetonitrile, and then stored at $-80^{\circ} \mathrm{C}$ until high-pressure liquid chromatography (HPLC) analysis.

$800 \mu \mathrm{l}$ sea water samples were procured from: (i) the reef flat of Heron Island Reef at $\sim 10 \mathrm{~cm}$ below sea surface at mid-tide (transferred back to Heron Island Research Station on ice); and (ii) artificial seawater made fromTrophic Marin Pro Reef sea salt mixed with reverse osmosis filtered tap water. For both sea water samples, $1 \mu$ norvaline solution was added, followed by evaporation and dissolving as described above, then stored at $-80^{\circ} \mathrm{C}$ until HPLC analysis.

Free amino acids were quantified using a high-throughput HPLC method as described in 26.

\section{Settlement and metamorphosis assays}

Larval metamorphosis assays were performed in sterile 6-well plates following 15. Newly-emerged larvae were incubated continuously in either $10 \mathrm{~mL} 0.22 \mu \mathrm{m}$ filtered sea water (FSW) or $10 \mathrm{~mL}$ amino acid-free artificial seawater (AF-SW, recipe from http://cshprotocols.cshlp.org/content/2012/2/pdb.rec068270.full). Each treatment consisted of 10 wells with 20 larvae per well. At 6 hpe, by which time all larvae would be competent to settle (27), freshly prepared shards of the inductive coralline algae Amphiroa fragilissima were added to five wells in both the FSW and AF-SW to induce settlement. The remaining 5 wells per treatment served as controls, with no inductive coralline algae added. Plates were kept in the dark at $25^{\circ} \mathrm{C}$ and the number of larvae settled and initiating metamorphosis was scored after $24 \mathrm{~h}$. 


\section{Enrichment and collection of symbiotic bacteria}

To isolate symbiotic bacteria, $\sim 5 \mathrm{~g}$ wet weight of freshly collected adult sponge tissue was dissected by sterile scalpel, cut into pieces, placed into individual $50 \mathrm{ml}$ falcon tubes containing ice cold calcium and magnesium free artificial seawater (CMF-SW) and agitated on a shaker table for 5 min at $200 \mathrm{rpm}$. The supernatant was discarded and the sponge tissue rinsed 5 times in CMF-SW. Sponge cells and bacterial symbionts were dissociated by squeezing the tissue with a syringe through $25 \mu \mathrm{m}$ mesh. The dissociated cells were centrifuged at $100 \mathrm{~g}$ for $15 \mathrm{~min}$ at $4{ }^{\circ} \mathrm{C}$ to separate the sponge cells (pellet) from the symbiont bacteria (supernatant). The supernatant containing the bacterial cells were transferred to a new $50 \mathrm{~mL}$ tube and re-centrifuged at $200 \mathrm{~g}$ for $15 \mathrm{~min}$ at $4^{\circ} \mathrm{C}$, and this step was repeated for a final centrifugation at $300 \mathrm{~g}$ for $15 \mathrm{~min}$ at $4{ }^{\circ} \mathrm{C}$. The final supernatant was filtered through a $5 \mu \mathrm{m}$ mesh, and the filtrate was centrifuged for $20 \mathrm{~min}$ at $8800 \mathrm{~g}$ and $4{ }^{\circ} \mathrm{C}$ to pellet the bacterial cells. The supernatant was then discarded and the bacterial cell pellet re-suspended in FSW (28). The final suspension was confirmed by microscopy to consist of $\sim 98 \%$ bacterial cells.

\section{Stable isotope tracer experiments}

Larvae collected at 0 hpe were separated into four $1.5 \mathrm{~mL}$ tubes each containing 10 individuals and incubated with 1.2 mL FSW + $1.2 \mu 110 \mathrm{mM}{ }^{13} \mathrm{C}$-arginine (Lot No. PR-21659, Catalog No. CLM2070-0, Cambridge Isotope Laboratories, Inc.). From each tube, $30 \mu 1$ of supernatant was removed every $2 \mathrm{~h}$ and processed for amino acids extraction as described above. The supernatants were analysed by LC-MS to determine the ${ }^{13} \mathrm{C} /{ }^{12} \mathrm{C}$-arginine changes in the $\mathrm{FSW}$.

Additional batches of 0 hpe larvae were incubated with $1.2 \mathrm{~mL} \mathrm{FSW}+1.2 \mu 110 \mathrm{mM}{ }^{13} \mathrm{C}$-arginine as above ( $\mathrm{n}=4$ replicates, 10 larvae per replicate). Larvae were collected 1 and $5 \mathrm{~h}$ post incubation and washed three times in $1.2 \mathrm{~mL} \mathrm{FSW} \mathrm{(centrifuged} \mathrm{at} 100 \mathrm{~g}$ for $3 \mathrm{~min}$ ) and processed for extraction of amino acids as described above. The extraction solutions were moved into vials by Zip-Tip C18 for LC-MS analysis to determine the relative ratios of ${ }^{13} \mathrm{C} /{ }^{12} \mathrm{C}$-arginine and ${ }^{13} \mathrm{C} /{ }^{12} \mathrm{C}$ citrulline.

Four aliquots of $200 \mu \mathrm{l}$ of the bacterial suspension obtained as described above were added to $2 \mu 1$ 10 mM ${ }^{13}$ C-citrulline (Lot No. PR-16536, Catalog No. CLM-4899-0, Cambridge Isotope Laboratories, Inc., Tewksbury, MA, USA). After $1 \mathrm{~h}$ of incubation, the bacteria were washed with FSW three times, centrifuged for $10 \mathrm{~min}$ at $8800 \mathrm{~g}$, and re-suspended in $1 \mathrm{~mL} \mathrm{FSW}$. Bacterial 
samples were collected 0 and $4 \mathrm{~h}$ post incubation ( $\mathrm{n}=3$ replicate samples for each time point) by centrifuging at $8800 \mathrm{~g}$ for $10 \mathrm{~min}$, and were processed for amino acid extraction as described above. The extracted solutions were moved into vials using Zip-Tip C18 (Millipore, Bedford, MA, USA) for gas chromatography-mass spectrometry (GC-MS) analysis to determine the relative ratios of ${ }^{13} \mathrm{C} /{ }^{12} \mathrm{C}$-arginine and ${ }^{13} \mathrm{C} /{ }^{12} \mathrm{C}$-citrulline.

\section{LC-MS}

LC-MS was carried out to quantify the proportion of arginine and citrulline either labelled or unlabelled with ${ }^{13} \mathrm{C}$ isotope. For LC-MS, $6 \mu$ laliquots were injected onto an Acquity UPLC CSH column $(300 \mu \mathrm{m} \times 100 \mathrm{~mm}, \mathrm{C}-18,1.7 \mu \mathrm{m}, 130 \AA$, Waters Corporation, Milford, MA, USA). The flowrate was $3 \mu \mathrm{min}^{-1}$ and the analytes were eluted using a gradient of $\mathrm{ACN}$ in $\mathrm{H}_{2} \mathrm{O}$. Initially, 3 $\min$ at $1 \% \mathrm{ACN}$, then $60 \%$ for $10 \mathrm{~min}$ and $95 \%$ for $12 \mathrm{~min}$, before returning to the initial $1 \% \mathrm{ACN}$ for $20 \mathrm{sec}$ and re-equilibration for a total run-time of $20 \mathrm{~min}$. The eluted analytes were mass analysed using an Exactive HF-X (Thermo Fischer Scientific, Walford, MA, USA) in targeted positive ion SIM mode with a resolution of 240,000. Five ions were targeted: 118.08626 (norvaline), 175.11896 (arginine), $176.19296\left({ }^{13} \mathrm{C}\right.$-arginine), 176.12762 (citrulline), 177.11163 $\left({ }^{13} \mathrm{C}\right.$-citrulline). Data were manually annotated using the Thermo Xcalibur Qual Browser software (Thermofisher).

\section{Statistics}

Data were analysed by one-way analysis of variance (ANOVA) with treatment as a factor in SPSS 22.0. Significant differences among treatments were detected by Tukey's honest significant difference post-hoc test. $\mathrm{P}$ values below 0.05 were considered significant. 


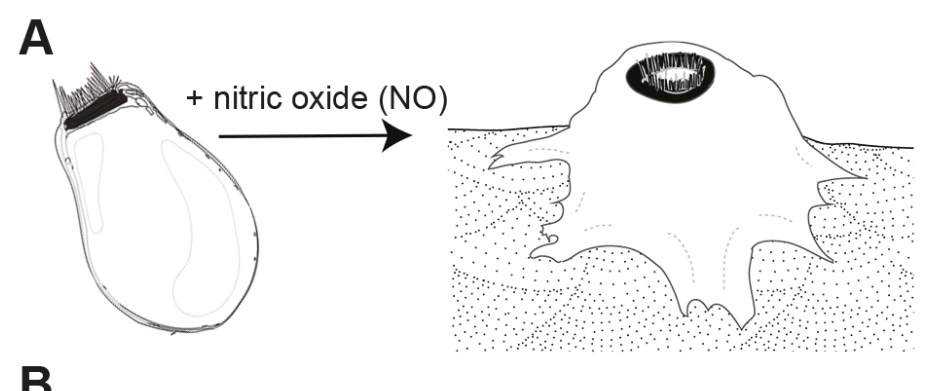

B
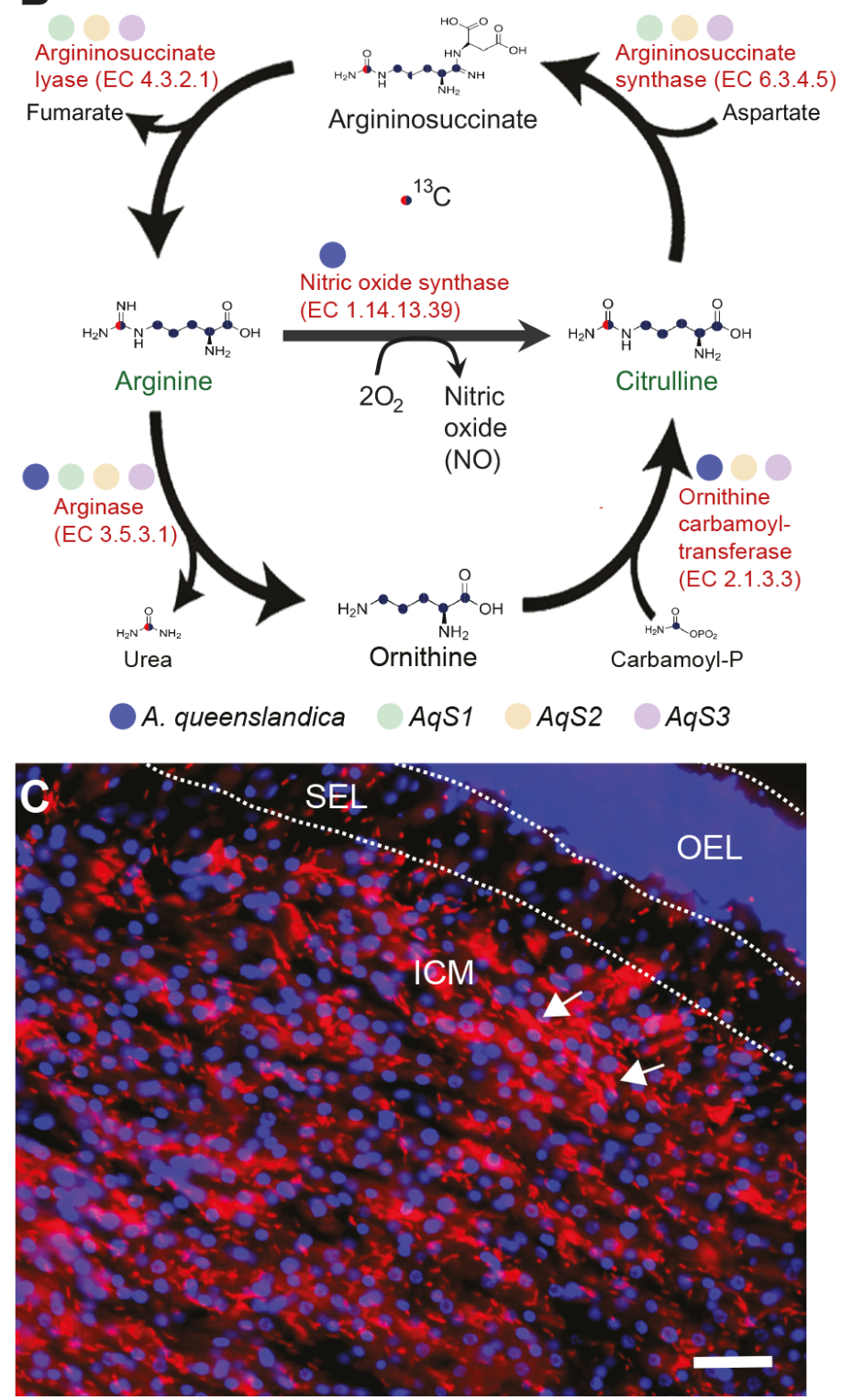

Figure 1. Amphimedon queenslandica cannot synthesize arginine, which is required for nitric oxideinduced settlement and metamorphosis. A. In A. queenslandica, nitric oxide (NO) is necessary for completion of larval settlement (Ueda et al.). B. Arginine, which is a necessary precursor for NO synthesis, cannot be synthesized the sponge. Its genome does not code for argininosuccinate synthase and argininosuccinate lyase, but both genes are present in its primary bacterial symbionts. Colored dots next to the enzymes comprising the arginine-citrulline synthesis loop correspond to presence in sponge and symbiont genomes. C. Fluorescence in situ hybridization (FISH) with an AqS1-specific 16S probe showing the distribution and abundance of this symbiont in the larval anterior. The outer epithelial layer (OEL), middle subepithelial layer (SEL) and inner cell mass (ICM) are shown. This symbiont is enriched in the inner cell mass (red; arrows pointing to examples); blue, DAPI-stained sponge cell nuclei. Scale bar $10 \mu \mathrm{m}$. 

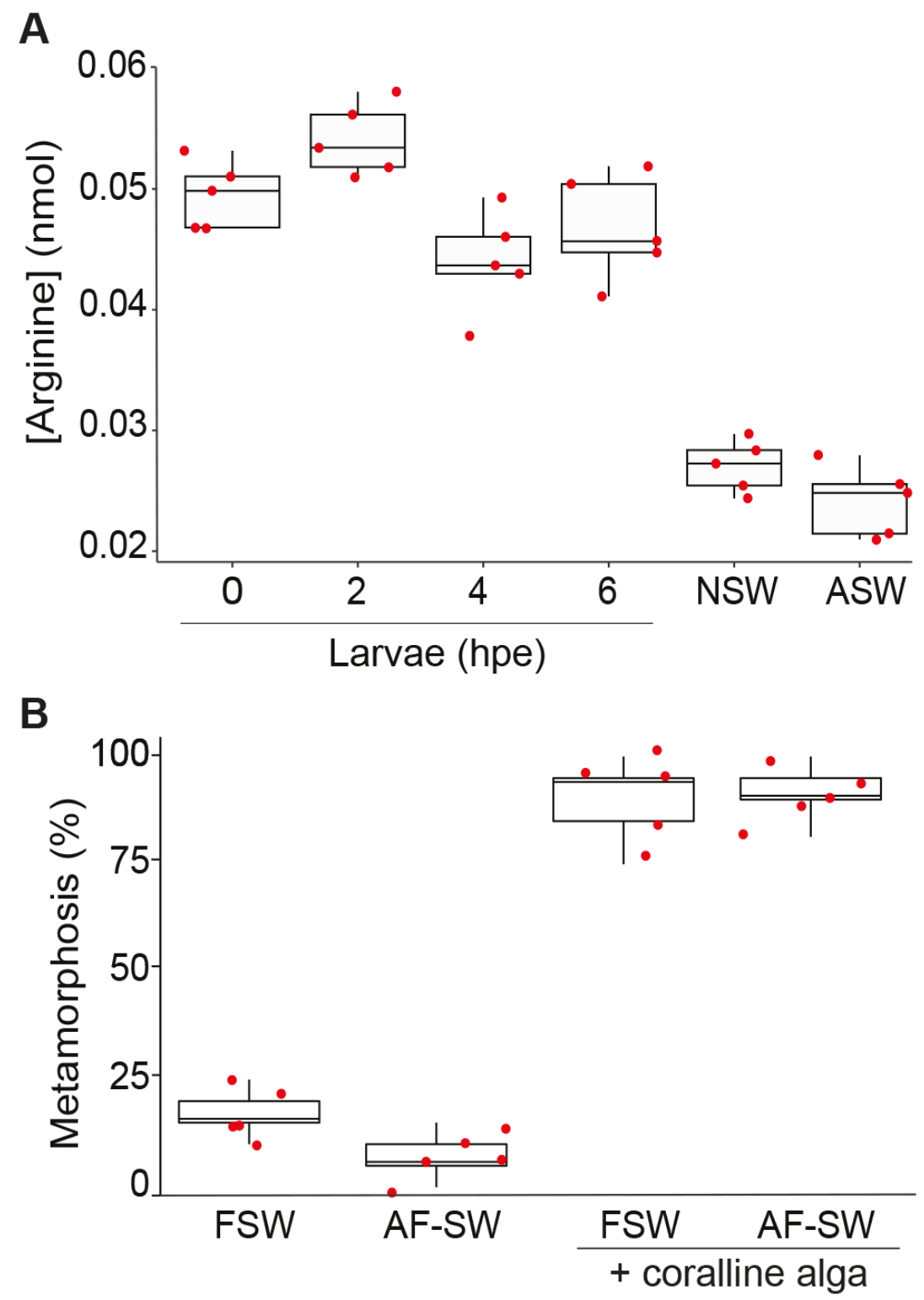

Figure 2. Exogenous arginine is not required for Amphimedon queenslandica larvae to settle and initiate metamorphosis. A. Arginine levels in individual larvae sampled at 0, 2, 4 and 6 hours postemergence (hpe) from adult sponges in their native habitat on Heron Island Reef, and in $1 \mathrm{ml}$ of natural sea water from Heron Island Reef (NSW) and of artificial seawater (ASW) made from commercial sea salts. Red dots, arginine levels in individual larvae or replicated water samples $(n=5)$. B. Percent of larvae that settled and initiated metamorphosis when reared in filtered sea water (FSW) or in arginine-free sea water (AF-SW), in the absence or presence of the inductive coralline alga Amphiroa fragilissima (15). Data are presented as the mean percentage of individuals that settled and initiated metamorphosis \pm SEM. Red dots, 5 replicates (20 larvae per replicate). 
Sponge larval holobiont

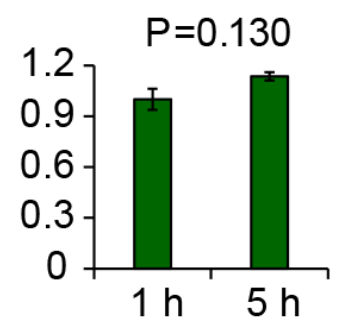

${ }^{13} \mathrm{C}-\mathrm{Arg} /{ }^{12} \mathrm{C}-\mathrm{Arg}$

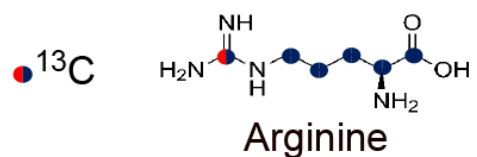

Symbiotic bacteria

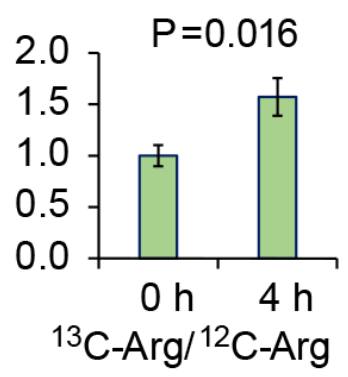

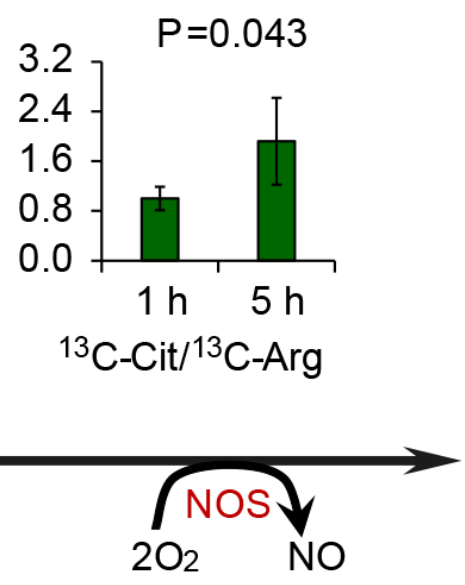
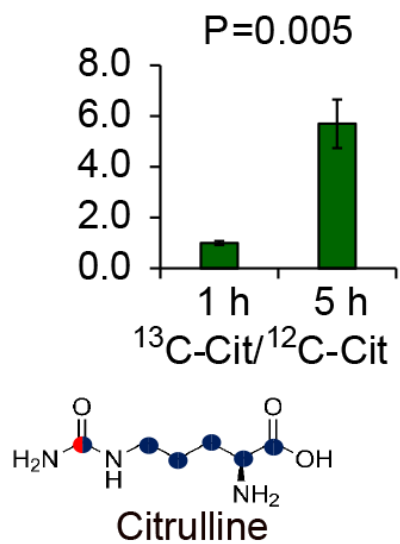

Citrulline

Figure 3. Evidence for arginine biosynthesis complementation between the sponge host and its bacterial symbionts. Relative changes in abundance of ${ }^{13} \mathrm{C}$ in arginine and citrulline in A. queenslandica and its symbionts. A. queenslandica larvae were incubated with ${ }^{13} \mathrm{C}$-arginine (dark green, top row) for 1 and $5 \mathrm{~h}$ and the abundance of ${ }^{12} \mathrm{C}$ - and ${ }^{13} \mathrm{C}$-citrulline, and ${ }^{12} \mathrm{C}$ - and ${ }^{13} \mathrm{C}$-arginine were measured. The ordinate shows the relative change in abundance, where abundance at $1 \mathrm{~h}$ is 1.0. Symbiotic bacteria were incubated with ${ }^{13} \mathrm{C}$-citrulline (light green, bottom row) for $1 \mathrm{~h}$ and the abundance of ${ }^{12} \mathrm{C}$ - and ${ }^{13} \mathrm{C}$-citrulline, and ${ }^{12} \mathrm{C}$ and ${ }^{13} \mathrm{C}$-arginine were measured at 1 and $4 \mathrm{~h}$. The ordinate shows the relative change in abundance, where abundance at $0 \mathrm{~h}$ is 1.0 . 


\section{References}

1. Leise EM, Thavaradhara K, Durham NR, Turner BE (2001). Serotonin and nitric oxide regulate metamorphosis in the marine snail Ilyanassa obsoleta. American Zoologist 41.

2. Bishop CD, Brandhorst BP (2003). On nitric oxide signaling, metamorphosis, and the evolution of biphasic life cycles. Evolution \& development 5: 542-550.

3. Bishop CD, Brandhorst BP (2007). Development of nitric oxide synthase-defined neurons in the sea urchin larval ciliary band and evidence for a chemosensory function during metamorphosis. Developmental Dynamics 236: 1535-1546.

4. Pechenik JA, Cochrane DE, Li W, West ET, Pires A, Leppo M (2007). Nitric oxide inhibits metamorphosis in larvae of Crepidula fornicata, the slippershell snail. The Biological Bulletin 213: $160-171$.

5. Castellano I, Ercolesi E, Palumbo A (2014). Nitric oxide affects erk signaling through downregulation of map kinase phosphatase levels during larval development of the ascidian Ciona intestinalis. PLOS ONE 9: e102907.

6. Ueda N, Degnan SM (2013). Nitric oxide acts as a positive regulator to induce metamorphosis of the ascidian Herdmania momus. PLOS ONE 8: e72797.

7. Ueda N, Degnan SM (2014). Nitric oxide is not a negative regulator of metamorphic induction in the abalone Haliotis asinina. Frontiers in Marine Science 1: 21.

8. Ueda N, Richards GS, Degnan BM, Kranz A, Adamska M, Croll RP et al (2016). An ancient role for nitric oxide in regulating the animal pelagobenthic life cycle: evidence from a marine sponge. Scientific reports 6: 37546.

9. Yang X-X, Wong YH, Zhang Y, Zhang G, Qian P-Y (2018). Exploring the regulatory role of nitric oxide (NO) and the NO-p38MAPK/cGMP pathway in larval settlement of the bryozoan Bugula neritina. Biofouling 34: 545-556.

10. Zhu Y-T, Zhang Y, Liu Y-Z, Li Y-F, Yoshida A, Osatomi K, Yang J-L, Liang X (2020). Nitric oxide negatively regulates larval metamorphosis in hard-shelled mussel (Mytilus coruscus). Frontiers in Marine Science 7: 00356.

11. Payne SH, Loomis WF (2006). Retention and loss of amino acid biosynthetic pathways based on analysis of whole-genome sequences. Eukaryotic Cell 5: 272-276.

12. Fieth RA, Gauthier M-EA, Bayes J, Green KM, Degnan SM (2016). Ontogenetic changes in the bacterial symbiont community of the tropical demosponge Amphimedon queenslandica: metamorphosis is a new beginning. Frontiers in Marine Science 3: 228.

13. Gauthier M-EA, Watson JR, Degnan SM (2016). Draft genomes shed light on the dual bacterial symbiosis that dominates the microbiome of the coral reef sponge Amphimedon queenslandica. Frontiers in Marine Science 3: 196.

14. Hadfield MG, Paul VJ (2001). Natural chemical cues for settlement and metamorphosis of marine invertebrate larvae. Marine Chemical Ecology 13: 431-461.

15. Say TE, Degnan SM (2020). Molecular and behavioural evidence that interdependent photo-and chemosensory systems regulate larval settlement in a marine sponge. Molecular Ecology 29: 247-261.

16. Srivastava M, Simakov O, Chapman J, Fahey B, Gauthier ME, Mitros T et al. (2010). The Amphimedon queenslandica genome and the evolution of animal complexity. Nature 466: 720726.

17. Manahan DT (1989). Amino acid fluxes to and from seawater in axenic veliger larvae of a bivalve (Crassostrea gigas). Mar Ecol Prog Ser 53: 247-255. 
18. Ren Q, Paulsen IT (2005). Comparative analyses of fundamental differences in membrane transport capabilities in prokaryotes and eukaryotes. PLoS Computational Biology 1: e27.

19. Woyke T, Teeling H, Ivanova NN, Huntemann M, Richter M, Gloeckner FO et al. (2006). Symbiosis insights through metagenomic analysis of a microbial consortium. Nature 443: 950.

20. Newton I, Woyke T, Auchtung T, Dilly G, Dutton R, Fisher M et al. (2007). The Calyptogena magnifica chemoautotrophic symbiont genome. Science 315: 998-1000

21. Kuwahara H, Yoshida T, Takaki Y, Shimamura S, Nishi S, Harada M et al (2007). Reduced genome of the thioautotrophic intracellular symbiont in a deep-sea clam, Calyptogena okutanii. Current Biology 17: 881-886.

22. Leys SP, Larroux C, Gauthier M, Adamska, M, Fahey B, Richards GS, Degnan SM, Degnan BM. (2008). Isolation of Amphimedon developmental material. Cold Spring Harb Protoc: doi: 101101/pdbprot5095

23. Larroux C, Fahey B, Adamska M, Richards GS, Gauthier M, Green K, Lovas E, Degnan BM. 2008. Whole-mount in situ hybridization in Amphimedon. Cold Spring Harb Protoc: doi: 101101/pdbprot5096

24. Webster, N., Hill, R. (2001). The culturable microbial community of the Great Barrier Reef sponge Rhopaloeides odorabile is dominated by an $\alpha$-Proteobacterium. Marine Biology 138: 843-851.

25. (Bartolomeo MP, Maisano F. (2006). Validation of a reversed-phase HPLC method for quantitative amino acid analysis. J Biomol Tech. 2:131-137.

26. Valgepea K, Lemgruber RSP, Meaghan K, Palfreyman RW et al. (2017). Maintenance of ATP homeostasis triggers metabolic shifts in gas-fermenting acetogens. Cell Systems 4: 505-515.

27. Degnan SM, Degnan BM. (2010). The initiation of metamorphosis as an ancient polyphenic trait and its role in metazoan life cycle evolution. Phil Trans $R$ Soc B 365: 641-651

28. Moitinho-Silva L, Díez-Vives C, Batani G, Esteves AIS, Jahn MT, Thomas T (2017). Integrated metabolism in sponge-microbe symbiosis revealed by genome-centered metatranscriptomics.

The ISME Journal 11: 1651-1666. 